\title{
Heritability of Fruit Rot Resistance in American Cranberry
}

\author{
Jennifer Johnson-Cicalese \\ Department of Plant Biology and Pathology, P.E. Marucci Center for Blueberry \& Cranberry \\ Research \& Extension, Rutgers, The State University of New Jersey, Chatsworth, NJ 08019 \\ James J. Polashock \\ USDA-ARS, GIFVL, P.E. Marucci Center for Blueberry \& Cranberry Research \& Extension, \\ Chatsworth, NJ 08019
}

Josh A. Honig and Jennifer Vaiciunas

Department of Plant Biology and Pathology, School of Environmental and Biological Sciences, Rutgers, The State University of New Jersey, New Brunswick, NJ 08901

Daniel L. Ward

Department of Plant Biology and Pathology, Rutgers Agricultural Research and Extension Center, Rutgers, The State University of New Jersey, Bridgeton, NJ 08302

\author{
Nicholi Vorsa ${ }^{1}$ \\ Department of Plant Biology and Pathology, P.E. Marucci Center for Blueberry \& Cranberry \\ Research \& Extension, Rutgers, The State University of New Jersey, Chatsworth, NJ 08019
}

\begin{abstract}
AdDITIONAL INDEX wORDs. Vaccinium macrocarpon, genotyping, midparent-offspring regression, narrow sense heritability
Abstract. Fruit rot is the primary threat to cranberry (Vaccinium macrocarpon) production in the northeastern United States, and increasingly in other growing regions. Efficacy of chemical control is variable because the disease is caused by a complex of pathogenic fungi. In addition, cranberries are often grown in environmentally sensitive areas, placing restrictions on chemical control measures. Thus, a major focus of the cranberry breeding program is to develop cultivars with improved fruit rot resistance (FRR). Several genetically diverse sources of FRR have been identified in our germplasm collection. However, the most resistant accessions lack one or more attributes; e.g., productivity, required for commercial acceptance. These resistant accessions were used in crosses with elite highyielding selections and in 2009, 1624 progeny from 50 crosses were planted in 2.3- $\mathrm{m}^{2}$ field plots. During 2011-13, under field conditions with very limited fungicide management, disease pressure was severe, allowing evaluation for FRR. Plots were rated on a 1-5 scale for incidence of fruit rot (where $1=0 \%$ to $20 \%$ rot and $5=81 \%$ to $100 \%$ rotted fruit), and rotted fruit counts were made from selected plots to validate the ratings. There was a good correlation in the ratings between years $(2011$ vs. $2012: r=0.59, P<0.0001 ; 2011$ vs. $2013: r=0.50, P<0.0001 ; 2012$ vs. $2013: r=0.62$, $P<0.0001)$, and between rot ratings and percent rotted fruit $(r=0.90, P<0.0001)$. Significant differences were found between and within families for FRR. High heritability estimates $\left(h^{2}=0.81\right)$ were obtained with midparent-offspring regression of mean fruit rot ratings, indicating additive genetic variance for FRR. Introgression of FRR into higher yielding genetic backgrounds was also accomplished, as some progeny exhibiting high FRR also had commercially viable yield $\left(>300 \mathrm{~g} / 0.09 \mathrm{~m}^{2}\right)$, as well as good berry size and color. Selections are being further evaluated for potential cultivar release.
\end{abstract}

Native to North America, the american cranberry is largely endemic to acidic soils of northeastern United States and southeastern Canada (Vander Kloet, 1983), but it is cultivated in a broad range of temperate climatic conditions. Domesticated in the mid-1800s (Eck, 1990), genetic improvement of cranberry through breeding has been limited. Some of the most widely grown cultivars are native selections or first-generation breeding selections released over 60 years ago. For example, 'Early Black' and 'Ben Lear' were selected from the wild in

Received for publication 2 Dec. 2014. Accepted for publication 3 Mar. 2015. This project was supported by USDA-SCRI under Grant 2008-51180-04878; the USDA National Institute of Food and Agriculture under Agriculture and Food Research Initiative Competitive Grant USDA-NIFA-2013-67013-21107; Ocean Spray Cranberries, Inc.; and NJ Cranberry \& Blueberry Research Council.

${ }^{1}$ Corresponding author. E-mail: vorsa@aesop.rutgers.edu.
1843 and 1901, respectively, and are still in use (Dana, 1983). Genetic improvement of the american cranberry was initiated in the 1930s, when the U.S. Department of Agriculture, in cooperation with the agricultural experiment stations of Massachusetts, New Jersey, and Wisconsin, initiated a breeding program largely directed toward development of "false-blossom" resistance (Eck, 1990). The program released six cultivars in the 1950s and 1960s, derived from first-generation breeding and selection cycle crosses. More recently, through additional breeding and selection cycles, cultivars with improved fruit quality (e.g., fruit anthocyanin content) and productivity have been released (Vorsa, 2010, 2012).

The North American cranberry industry faces many challenges in the 21 st century, including increasing disease and insect pressures, likely exacerbated by a warming climate and increasing restrictions on insecticide and fungicide use. A major 
threat to the industry is fruit rot. Cranberry fruit rot is caused by a complex of fungi from at least 12 genera (Oudemans et al., 1998). In New Jersey, 25\% fruit loss is common, even with multiple, carefully timed fungicide applications beginning during mid-bloom. Without fungicides, losses can reach 100\%. Furthermore, fruit rot is becoming a serious problem in other major growing regions, including Wisconsin (McManus, 1998, 2006), where over half of the nation's cranberry crop is produced, and Massachusetts (University of Massachusetts, 2012). Moreover, due to consumer concern regarding food safety, environmental impacts, and worker safety, stricter pesticide use regulations are being implemented (Byrne, 2012). For example, California's Proposition 65 includes on its list of potential carcinogens one of the principal fungicides used in cranberry fruit rot control, chlorothalonil (California Office of Environmental Health Hazard Assessment, 2015). There are also concerns over pending changes to the European Union's maximum residue levels that could effectively eliminate chlorothalonil use on fruit and fruit products destined for Europe (European Commission, 2015).

Throughout the world, fruit crop-breeding programs are increasingly targeting disease resistance (Byrne, 2012), including the Rutgers/NJAES cranberry breeding program. Current cultivars are high-yielding and widely adapted, but lack sufficient fruit rot resistance (FRR). Fruit rot resistance would be especially valuable for the northeastern U.S. cranberry growing region.

Toward this objective, a diverse cranberry germplasm collection was evaluated for field fruit rot incidence during 2003-04 at the P.E. Marucci Center in Chatsworth, NJ with the goal of identifying sources of resistance (Johnson-Cicalese et al., 2009). Under severe disease pressure, accessions having some level of resistance were identified. Initial DNA fingerprinting using sequence characterized amplified regions (SCAR) markers (Polashock and Vorsa, 2002) identified four genetic types, Budds Blues-type, Holliston-type, US89-3, and 'Cumberland', suggesting diverse sources of resistance existed in the germplasm. However, the resistant accessions did not have adequate productivity. These accessions were used in crosses with the ultimate goal of introgressing FRR into productive backgrounds. The objectives of this study were to: 1) determine heritability of field FRR from an array of crosses using midparent-offspring regression; 2) further genetically define the resistant germplasm using SSR markers; and 3) determine the relationship between resistance and productivity.

\section{Materials and Methods}

GENOTYPING OF FRUIT ROT RESISTANT GERMPLASM. To better define genetic relationships among resistant accessions, and increase resolution among the phenotypically similar accessions, additional fingerprinting was done using 34 simple sequence repeat (SSR) markers developed as part of a cranberry genome mapping project (Georgi et al., 2012). Also included in the analysis were several accessions that showed moderate FRR in 2003-04: US88-67 (aka 'Wales Henry', originally collected in Carver, MA) and US88-97 (aka 'Paradise Meadow', Sharon, MA) (Chandler and Demoranville, 1958); US88-121 (cultivated selection of unknown origin); and NJ91-13-7 (native selection, Pilgrim Lake, MA) (Bruederle et al., 1996). NJ09-2 and NJ09-5 (aka 'Bugle', originally from Sandwich, MA, collected by F. Caruso) were included because they are purported to have some FRR.
Leaf material was harvested from all selected accessions and ground with a mortar and pestle in liquid nitrogen. DNA was isolated using a CTAB DNA isolation procedure (Stewart and Via, 1993). For genotyping, amplifications of SSR loci with fluorescently labeled PCR primers were performed in $13-\mu \mathrm{L}$ reactions using $5 \mathrm{ng}$ of cranberry DNA, 1X Ramp-Taq PCR buffer (Denville Scientific, Metuchen, NJ), $2 \mathrm{mM} \mathrm{MgCl}_{2}, 0.25$ mM each dNTP, $0.5 \mathrm{U}$ Ramp-Taq DNA polymerase (Denville Scientific), 0.5 pmol forward primer with the 18-bp M13(-21) addition at the $5^{\prime}$-end (Schuelke, 2000), 1 pmol reverse primer, and 1 pmol fluorescent dye-labeled (FAM, NED, PET, or VIC) 18 bp M13(-21) primer. Thermal-cycling parameters were 94 ${ }^{\circ} \mathrm{C}$ for $5 \mathrm{~min}$, followed by 30 cycles of $94^{\circ} \mathrm{C}$ for $30 \mathrm{~s}, 55^{\circ} \mathrm{C} 45 \mathrm{~s}$, $72{ }^{\circ} \mathrm{C} 45 \mathrm{~s}$, followed by 20 cycles of $94{ }^{\circ} \mathrm{C}$ for $5 \mathrm{~min}, 53{ }^{\circ} \mathrm{C}$ for $45 \mathrm{~s}, 72^{\circ} \mathrm{C}$ for $45 \mathrm{~s}$, ending with a final extension for $72{ }^{\circ} \mathrm{C}$ for $10 \mathrm{~min}$. PCR reaction products were analyzed on an ABI 3500xl Genetic Analyzer (Applied Biosystems, Foster City, CA) and sized and scored using LIZ 600 size standard and Genemapper 5.0 (Applied Biosystems).

GENETIC DisTANCE AND UPGMA CLUSTERING. Only reliable and well-amplified SSR marker alleles were scored and assembled into a diploid allelic data matrix. Data calculations for shared allele frequencies, genetic distance (proportion of shared alleles), and 1000 bootstrap analyses were calculated using PowerMarker v3.25 (Liu and Muse, 2005). An unweighted pair group method with arithmetic mean (UPGMA) dendrogram was constructed from the genetic distance matrices using MEGA6 (Tamura et al., 2013). Bootstrap values for the UPGMA dendrogram were calculated using the CONSENCE program module of PHYLIP v3.69 (Felsenstein, 2009).

Crosses DERIVED FROM FRUIT ROT-RESISTANT GERMPLASM. Progeny evaluated in this study were derived from crosses made in 2005 and 2006 in a greenhouse using potted plants. Parents included elite high-yielding cultivars and selections: Crimson Queen, Mullica Queen, Demoranville, Stevens, NJS98-62, and NJS98-76; fruit rot-resistant germplasm: Budd's Blues (US88-30, US88-126, US93-34, and US94176), Holliston (US88-1), Cumberland (US88-79), and US89-3; and several advanced selections with moderate resistance: CNJ97-86-45, CNJ97-86-46, CNJ98-164-37, and CNJ98-154-26 (Johnson-Cicalese et al., 2009; J. Johnson-Cicalese and N. Vorsa, unpublished data) (Table 1). Flowers were emasculated 1-2 d before anthesis and hand-pollinated 5-7 d later, when stigmas were receptive. Mature fruit from crosses were harvested, seeds were extracted and germinated, and seedlings grown out in the greenhouse. Seedlings were clonally propagated to produce 24 cuttings per seedling, for establishment of field plots. The number of seedlings per cross ranged from 17 to 46 , depending on the success of the cross (Table 2).

Field plots and progeny evaluation. A field trial was established in May 2009, consisting of 1626 progeny planted in $2.25-\mathrm{m}^{2}$ plots in a 2-ha bed at the P.E. Marucci Center in Chatsworth, NJ. Two subsets of progeny from each of the 50 crosses were planted in two blocks using a randomized complete block design (RCBD). Plots of parents were also planted in this trial, in three complete blocks. The trial was maintained under standard grower practices in terms of harvesting, water management, fertilization, and pesticide applications. In 2011, the plots were adequately established (complete vine cover, with upright density to yield $>50$ fruit $/ \mathrm{dm}^{2}$ ) to begin evaluating for FRR. To promote a high-incidence of fruit rot disease, selected fungicide applications were withheld. In 2011, only 
Table 1. Performance of parents used in cranberry crosses, means of data collected 15 Sept. 2011, 8 Aug. 2012, 7 Sept. 2012 , and 2 Aug. 2013. Means followed by different letters are significantly different by Tukey-Kramer means separation test at $P \leq 0.05$.

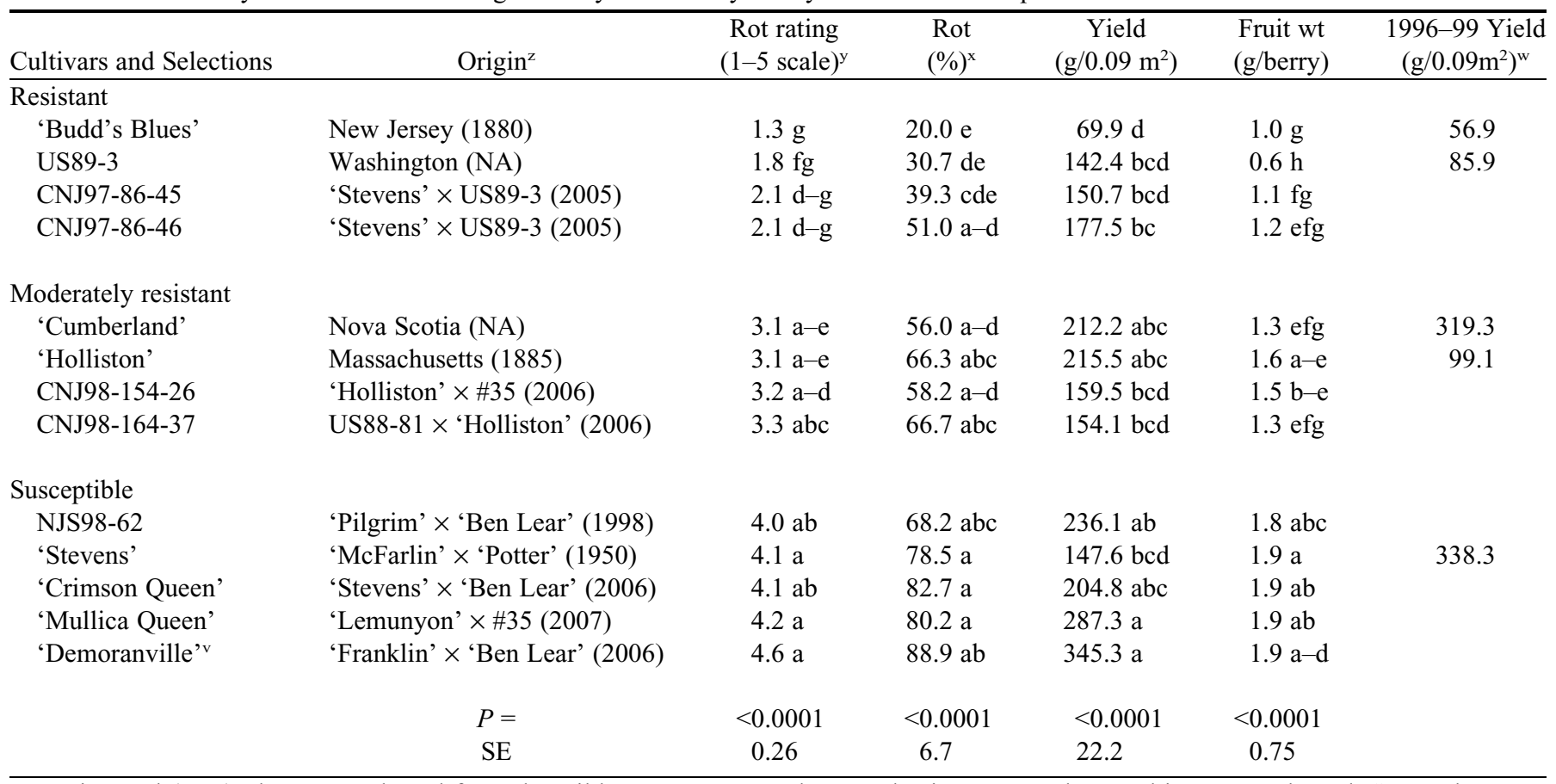

${ }^{\mathrm{z}}$ Location and (year) plant was selected from the wild, or parentage and year selection was made or cultivar was released. Some plants are experimental selections from our breeding program; NA $=$ date not available.

${ }^{\mathrm{y}}$ Rot rating is a visual estimate of the amount of rotted fruit using a scale of $1-5$, where $1=0 \%$ to $20 \%$ rot and $5=81 \%$ to $100 \%$ rot.

${ }^{x}$ Percent rotted fruit per $0.09-\mathrm{m}^{2}$ sample.

wMean yield from previous single plot evaluations collected from 1996 to 1999.

'Only one plot of 'Demoranville'.

three of the typical five applications were applied: mancozeb was applied at early bloom ( 3 June), and fenbuconazole and azoxystrobin on 13 and 23 June. Commercially typical fourth and fifth chlorothalonil applications were withheld. In 2012, only one application of fenbuconazole/azoxystrobin was applied on 13 June, and in 2013 no fungicides were applied.

All plots were rated for fruit rot on 20 Sept. 2011, 29 Aug. 2012, and 2 Aug. 2013, using a $1-5$ scale where $1=0 \%$ to $20 \%$ of the fruit were rotted, and $5=81 \%$ to $100 \%$ rotted fruit. Plots where individual berries were generally partially rotted received a lower rating than plots where berries were completely rotted. Evaluation dates were based on when susceptible controls approached $70 \%$ rotted fruit. Disease pressure increased each year, due to fewer fungicide applications and increasing inoculum load, requiring earlier season evaluations. A $0.09-\mathrm{m}^{2}$ sample was harvested each year from a subset of plots: all plots of parents (15 Sept. 2011, 8 Aug. and 7 Sept. 2012, and 2 Aug. 2013), and five randomly selected progeny per cross (three from the first block and two from the second; 30 Sept. 2011, 6 Sept. 2012, and 2 Aug. 2013) for midparentoffspring regression analysis. Additional $0.09-\mathrm{m}^{2}$ samples were harvested from progeny with exceptionally low rot ratings. These plots were evaluated for yield $\left(\mathrm{g} / 0.09 \mathrm{~m}^{2}\right)$, average berry weight, and percent rotted fruit (Georgi et al., 2013; JohnsonCicalese et al., 2009, 2011; Vorsa and Johnson-Cicalese, 2012).

SURVEY OF FUNGAL SPECIES PRESENT. Fruit were collected from the parental field plots on 8 Aug. 2012, 11 Sept. 2012, and 21 Aug. 2013 from three resistant ('Budd's Blues', US89-3, and 'Cumberland') and three susceptible ('Mullica Queen', 'Stevens', NJS98-62) selections, three replicates of each, 16 fruit per selection per replication (eight sound and eight rotted if possible; sometimes sound fruit could not be found). Berries were surface disinfested $(70 \% \mathrm{EtOH}$ for $30 \mathrm{~s}$, rinsed with water, $10 \%$ chlorine bleach for $3 \mathrm{~min}$ ), then plated (four berry halves per plate, four plates per selection) on potato dextrose agar (PDA). Antibiotics were added to the medium (streptomycin $40 \mathrm{mg} \cdot \mathrm{L}^{-1}$ and tetracycline $50 \mathrm{mg} \cdot \mathrm{L}^{-1}$ ) for fruit collected on 8 Aug. 2012. Antibiotics were subsequently deemed unnecessary to inhibit bacterial growth and were not added to the medium for the later collections (11 Sept. 2012 and 21 Aug. 2013). Fruit collected 11 Sept. 2012 were almost all rotted, so we were unable to culture sound berries from all selections. On 21 Aug. 2013, fruit (eight sound and eight rotted) were also collected from three highly resistant progeny and plated to determine the species of fungi present. Plates were incubated at room temperature and evaluated after 5-7 d. Fungi growing on the plates were identified by morphological characters (Polashock et al., 2009). Frequency of each fungal species was tabulated as percentage of the total number of fungal isolates scored.

Data analyses. Parents were compared using analysis of variance [ANOVA (3 years, three blocks)] and Tukey-Kramer means separation tests. Family means (3 years, two blocks) were also analyzed using ANOVA. Frequency distributions of rot ratings (using 2011-13 means) were calculated for each cross. Pearson's correlation coefficient was calculated to assess the relationships of data between pairs of years, and between fruit rot ratings and percent rotted fruit. To estimate heritability of FRR based on fruit rot ratings, midparent-offspring 
Table 2. Cranberry crosses made for fruit rot resistance and performance of the progeny, mean of data collected in 2011-13.

\begin{tabular}{|c|c|c|c|c|c|c|c|}
\hline Cross $^{z}$ & $\begin{array}{c}\text { Progeny } \\
\text { evaluated (no.) }\end{array}$ & $\begin{array}{c}\text { Resistant } \\
\text { progeny (no.) } \text { ( }^{\mathrm{y}}\end{array}$ & $\begin{array}{l}\text { Mean progeny rot } \\
\text { rating }(1-5 \text { scale })^{\mathrm{x}}\end{array}$ & $\begin{array}{l}\text { Deviation from } \\
\text { midparent }{ }^{\mathrm{w}}\end{array}$ & $\begin{array}{c}\text { Rotted } \\
\text { fruit }(\%)^{\mathrm{v}}\end{array}$ & $\begin{array}{c}\text { Yield } \\
\left(\mathrm{g} / 0.09 \mathrm{~m}^{2}\right)\end{array}$ & $\begin{array}{l}\text { Fruit wt } \\
\text { (g/berry) }\end{array}$ \\
\hline \multicolumn{8}{|c|}{ Resistant $\times$ resistant } \\
\hline $\mathrm{BB} \times \mathrm{BB}$ & 22 & 4 & $2.6 \mathrm{a}-\mathrm{e}$ & -1.2 & & & \\
\hline $\mathrm{BB} \times 86-45$ & 46 & 18 & $2.5 \mathrm{a}-\mathrm{c}$ & -0.7 & 41.9 & 160.0 & 1.2 \\
\hline $\mathrm{BB} \times 86-46$ & 46 & 24 & $2.4 \mathrm{a}-\mathrm{c}$ & -0.6 & & & \\
\hline $\mathrm{BB} \times 164-37$ & 24 & 5 & $3.2 \mathrm{e}-\mathrm{k}$ & -1.0 & & & \\
\hline $\mathrm{BB} \times \mathrm{Cum}$ & 20 & 4 & $2.6 \mathrm{a}-\mathrm{d}$ & -0.6 & & & \\
\hline $\mathrm{BB} \times \mathrm{Cum}$ & 24 & 14 & $2.2 \mathrm{a}$ & -0.1 & & & \\
\hline $\mathrm{Cum} \times \mathrm{BB}$ & 46 & 11 & $2.7 \mathrm{~b}-\mathrm{f}$ & -0.6 & 37.5 & 173.9 & 1.1 \\
\hline $\mathrm{BB} \times$ Holl & 46 & 10 & $2.9 \mathrm{c}-\mathrm{h}$ & -0.7 & 64.1 & 168.1 & 1.3 \\
\hline $89-3 \times 164-37$ & 24 & 2 & $3.3 \mathrm{~g}-\mathrm{m}$ & -0.8 & 66.4 & 216.4 & 1.0 \\
\hline Cum $\times 89-3$ & 46 & 11 & $2.7 \mathrm{~b}-\mathrm{f}$ & -0.4 & 51.4 & 230.9 & 1.2 \\
\hline Cum $\times 164-37$ & 24 & 0 & $3.6 \mathrm{j}-\mathrm{q}$ & -0.5 & & & \\
\hline Holl × 86-45 & 46 & 6 & $3.3 \mathrm{~g}-\mathrm{k}$ & -0.8 & 54.0 & 174.2 & 1.1 \\
\hline \multicolumn{8}{|c|}{ Resistant $\times$ susceptible } \\
\hline $\mathrm{BB} \times \mathrm{CQ}$ & 24 & 5 & $3.2 \mathrm{f}-\mathrm{k}$ & -0.7 & & & \\
\hline $\mathrm{BB} \times \mathrm{CQ}$ & 36 & 9 & $3.0 \mathrm{~d}-\mathrm{i}$ & -0.4 & 71.8 & 235.4 & 1.6 \\
\hline $\mathrm{BB} \times \mathrm{CQ}$ & 40 & 2 & $3.81-\mathrm{s}$ & -1.1 & & & \\
\hline $\mathrm{BB} \times \mathrm{DE}$ & 44 & 3 & $3.3 \mathrm{~g}-1$ & -0.6 & & & \\
\hline $\mathrm{BB} \times \mathrm{DE}$ & 40 & 3 & $3.6 \mathrm{k}-\mathrm{r}$ & -0.8 & 73.1 & 190.1 & 1.5 \\
\hline $\mathrm{BB} \times \mathrm{MQ}$ & 24 & 2 & $3.3 \mathrm{f}-\mathrm{k}$ & -0.6 & 77.9 & 202.3 & 1.4 \\
\hline $\mathrm{BB} \times \mathrm{MQ}$ & 46 & 1 & $4.1 \mathrm{q}-\mathrm{v}$ & -1.3 & 75.5 & 239.0 & 1.6 \\
\hline $\mathrm{Cum} \times \mathrm{CQ}$ & 36 & 0 & $4.1 \mathrm{r}-\mathrm{V}$ & -0.7 & & & \\
\hline $\mathrm{CQ} \times \mathrm{Cum}$ & 24 & 2 & $3.9 \mathrm{n}-\mathrm{t}$ & -0.5 & 85.1 & 262.5 & 1.6 \\
\hline Cum $\times$ DE & 38 & 0 & $4.4 \mathrm{t}-\mathrm{v}$ & -0.7 & 92.9 & 223.5 & 1.6 \\
\hline $\mathrm{DE} \times \mathrm{Cum}$ & 22 & 4 & $3.4 \mathrm{~h}-\mathrm{n}$ & 0.2 & 62.4 & 361.5 & 1.8 \\
\hline $\mathrm{Cum} \times \mathrm{MQ}$ & 44 & 0 & $4.2 \mathrm{~s}-\mathrm{v}$ & -0.6 & 80.7 & 325.7 & 1.7 \\
\hline Cum $\times 98-76$ & 20 & 0 & $4.3 \mathrm{~s}-\mathrm{v}$ & NA & & & \\
\hline Holl × 98-76 & 33 & 0 & $4.5 \mathrm{v}$ & NA & & & \\
\hline CQ $\times$ Holl & 46 & 0 & $4.4 \mathrm{t}-\mathrm{v}$ & -0.9 & 88.2 & 229.6 & 1.7 \\
\hline $\mathrm{CQ} \times 164-37$ & 24 & 0 & $4.3 \mathrm{~s}-\mathrm{V}$ & -0.7 & & & \\
\hline $\mathrm{MQ} \times 164-37$ & 24 & 0 & $3.9 \mathrm{~m}-\mathrm{t}$ & -0.1 & & & \\
\hline $\mathrm{MQ} \times 86-46$ & 46 & 3 & $3.5 \mathrm{i}-\mathrm{O}$ & -0.3 & 76.7 & 219.4 & 1.5 \\
\hline $98-62 \times \mathrm{BB}$ & 28 & 1 & $3.6 \mathrm{i}-\mathrm{q}$ & -0.8 & & & \\
\hline $98-62 \times$ Cum & 46 & 0 & $3.9 \mathrm{o}-\mathrm{t}$ & -0.4 & 73.2 & 227.6 & 1.4 \\
\hline $98-62 \times$ Holl & 24 & 0 & $4.5 \mathrm{v}$ & -1.0 & 86.5 & 194.8 & 1.6 \\
\hline
\end{tabular}

Continued next page

regression (2011-13 mean) was performed using the mean of the two parents vs. the mean of the progeny for 46 crosses. The slope of this regression line estimates $h^{2}$ (Falconer, 1989). For heritability estimation of percent rotted fruit, yield, and fruit size, data from five randomly selected progeny from each of 25 crosses were used. The MIXED procedure of SAS (version 4.3; SAS Institute, Cary, NC) was used to perform ANOVA on fruit rot ratings for a subset of 17 resistant by susceptible crosses (an almost complete diallel). The mixed effects model used contrasts to test for general combining ability, main effects of 
Table 2. Continued.

\begin{tabular}{|c|c|c|c|c|c|c|c|}
\hline Cross $^{z}$ & $\begin{array}{c}\text { Progeny } \\
\text { evaluated (no.) }\end{array}$ & $\begin{array}{c}\text { Resistant } \\
\text { progeny (no.) }\end{array}$ & $\begin{array}{l}\text { Mean progeny rot } \\
\text { rating }(1-5 \text { scale })^{\mathrm{x}}\end{array}$ & $\begin{array}{l}\text { Deviation from } \\
\text { midparent }^{\mathrm{w}}\end{array}$ & $\begin{array}{l}\text { Rotted } \\
\text { fruit }(\%)^{\mathrm{v}}\end{array}$ & $\begin{array}{c}\text { Yield } \\
\left(\mathrm{g} / 0.09 \mathrm{~m}^{2}\right)\end{array}$ & $\begin{array}{l}\text { Fruit wt } \\
\text { (g/berry) }\end{array}$ \\
\hline
\end{tabular}

Susceptible $\times$ susceptible

$\begin{array}{lcllrrr}\mathrm{MQ} \times 98-62 & 24 & 1 & 4.3 \mathrm{~s}-\mathrm{v} & -0.2 & & \\ 98-62 \times \mathrm{MQ} & 24 & 0 & 4.4 \mathrm{uv} & -0.3 & 93.1 & 226.5 \\ \mathrm{ST} \times 98-62 & 24 & 1 & 4.0 \mathrm{p}-\mathrm{v} & 0.0 & 79.8 & 264.9 \\ 98-62 \times \mathrm{ST} & 24 & 0 & 4.2 \mathrm{~s}-\mathrm{v} & -0.2 & 1.7 \\ & P= & & 0.001 & & 0.002 & 0.032\end{array}$

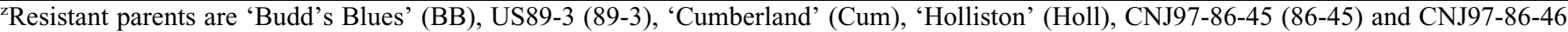
(86-46), CNJ98-164-37 (164-37), and NJ98-154-26 (154-26). Susceptible parents are the high-yielding cultivars 'Crimson Queen' (CQ), 'Mullica Queen' (MQ), 'Demoranville' (DE), 'Stevens' (ST), NJS98-76 (98-76), and NJS98-62 (98-62) (see Table 1).

'Number of progeny with a 3-year mean fruit rot rating of 2.2 or less.

${ }^{x}$ Rot rating is a visual estimate of the amount of rotted fruit using a scale of $1-5$, where $1=0 \%$ to $20 \%$ rot and $5=81 \%$ to $100 \%$ rot. Rot rating means followed by the same letter are not significantly different according to Tukey-Kramer mean separation test, $P \leq 0.05$.

wDeviation of the progeny means from the midparent value.

Proportion of rotted fruit per $0.09-\mathrm{m}^{2}$ sample. Rotted fruit, yield, and fruit weight data from five randomly selected progeny per cross, 25 crosses. "NA = not available; not included in heritability estimate because parental values for NJS98-76 not available.

susceptible parentage, resistant parentage, and the interaction between susceptible and resistant parentage.

Fungal survey data were analyzed with the GLM procedure of SAS to perform ANOVA to compare fungal frequencies found in fruit rot-resistant vs. susceptible cranberry selections. The three resistant and three susceptible selections were treated as subsamples in this analysis. In the August samples, fungal frequencies in sound vs rotted fruit were compared.

\section{Results and Discussion}

GENOTYPING FRUIT ROT RESISTANT GERMPlasm. Confirming previous conclusions based on SCARs (Johnson-Cicalese et al., 2009), SSR markers indicated the four sources of resistance used in crosses in this study are genetically distinct types: 1) Holliston-type, 2) Budd's Blues-type, 3) 'Cumberland', and 4) US89-3 (Fig. 1). All four resistance types appear widely separated from each other. 'Holliston' and 'Cumberland' are the most similar to each other, yet still differ by a distance coefficient of 0.32 ( 0 to 1 scale). Each of these types may offer different FRR loci/genes, affording the opportunity to pyramid these genes through breeding cycles and potentially increase resistance. The dendrogram indicates that some clones from the germplasm collection, given different accession numbers, are genotypically the same based on SSRs; i.e., US88-30, US94176, etc., are all 'Budd's Blues'. However, US93-34 differs from the other 'Budd's Blues' by one SSR marker; and a number of the accessions in the 'Holliston' group differ by one SSR marker. Genetic distances of FRR accessions from different geographic regions; e.g., 'Holliston' (MA) vs. 'Budd's Blues' (NJ) vs. 'Cumberland' (NS), are similar to those within regions, 'Holliston' (MA) vs. NJ91-13-7 (MA) vs. US88-67 (MA) (Fig. 1). Bruederle et al. (1996) found most genetic variation $(78.8 \%)$ was within cranberry populations vs. between populations of different regions. All the FRR accessions are highly heterozygous exhibiting $65 \%$ to $77 \%$ heterozygous SSR loci.

The germplasm accessions US88-121, NJ09-2, NJ09-5, US88-67, NJ91-13-7, and US88-97 (found to have moderate resistance), appear to be unrelated to one another, or to the four resistance types. NJ09-2 exhibits the least distance from US89-3,

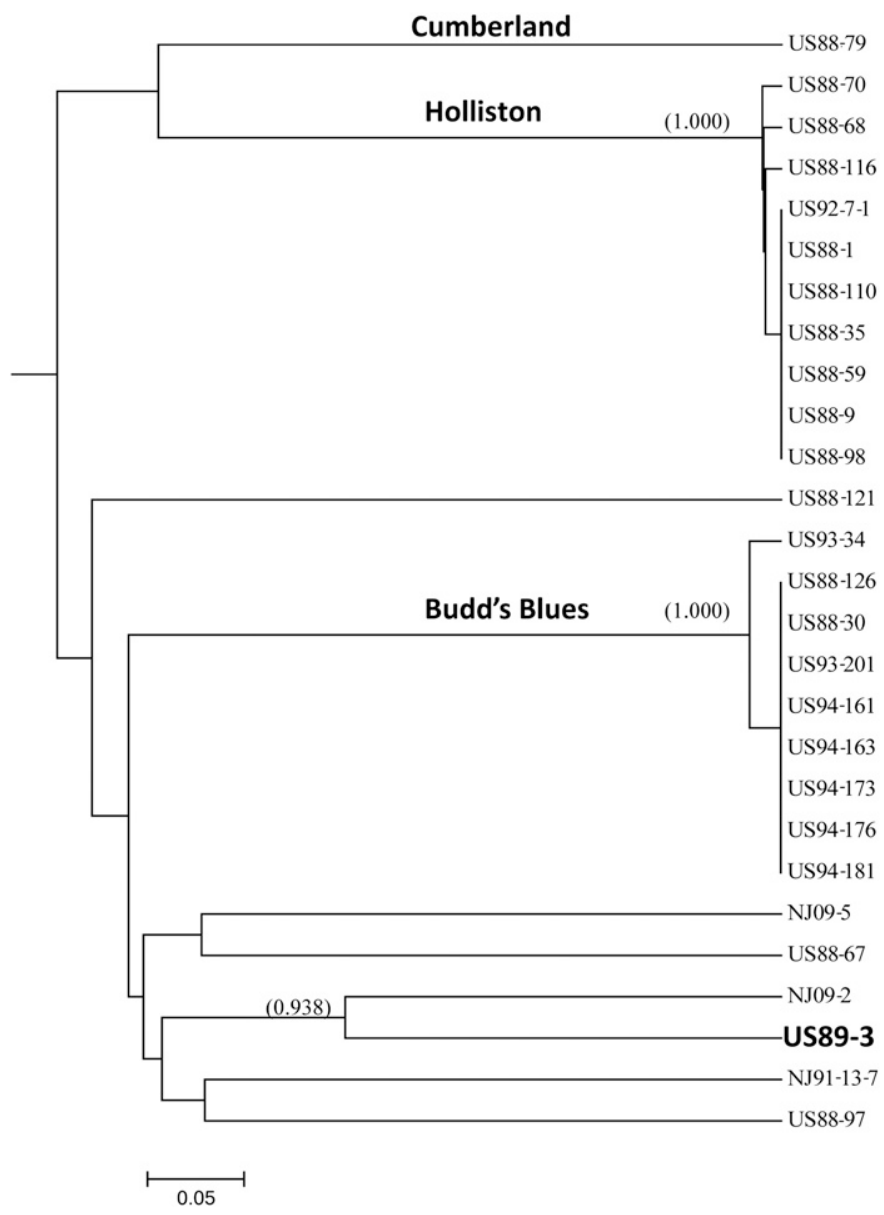

Fig. 1. Dendrogram showing genetic relationship of fruit rot-resistant cranberry accessions. UPGMA dendrogram was constructed from the genetic distance matrices using MEGA6 (Tamura et al., 2013) and bootstrap values were calculated using the CONSENCE program module of PHYLIP v3.695 (Felsenstein, 2009). Four resistant types are in bold font.

but has not exhibited resistance in our field plots (J. JohnsonCicalese and N. Vorsa, unpublished data).

Parent evaluation. Evaluation of the FRR parent accessions in replicated trials, under severe fruit rot pressure, 

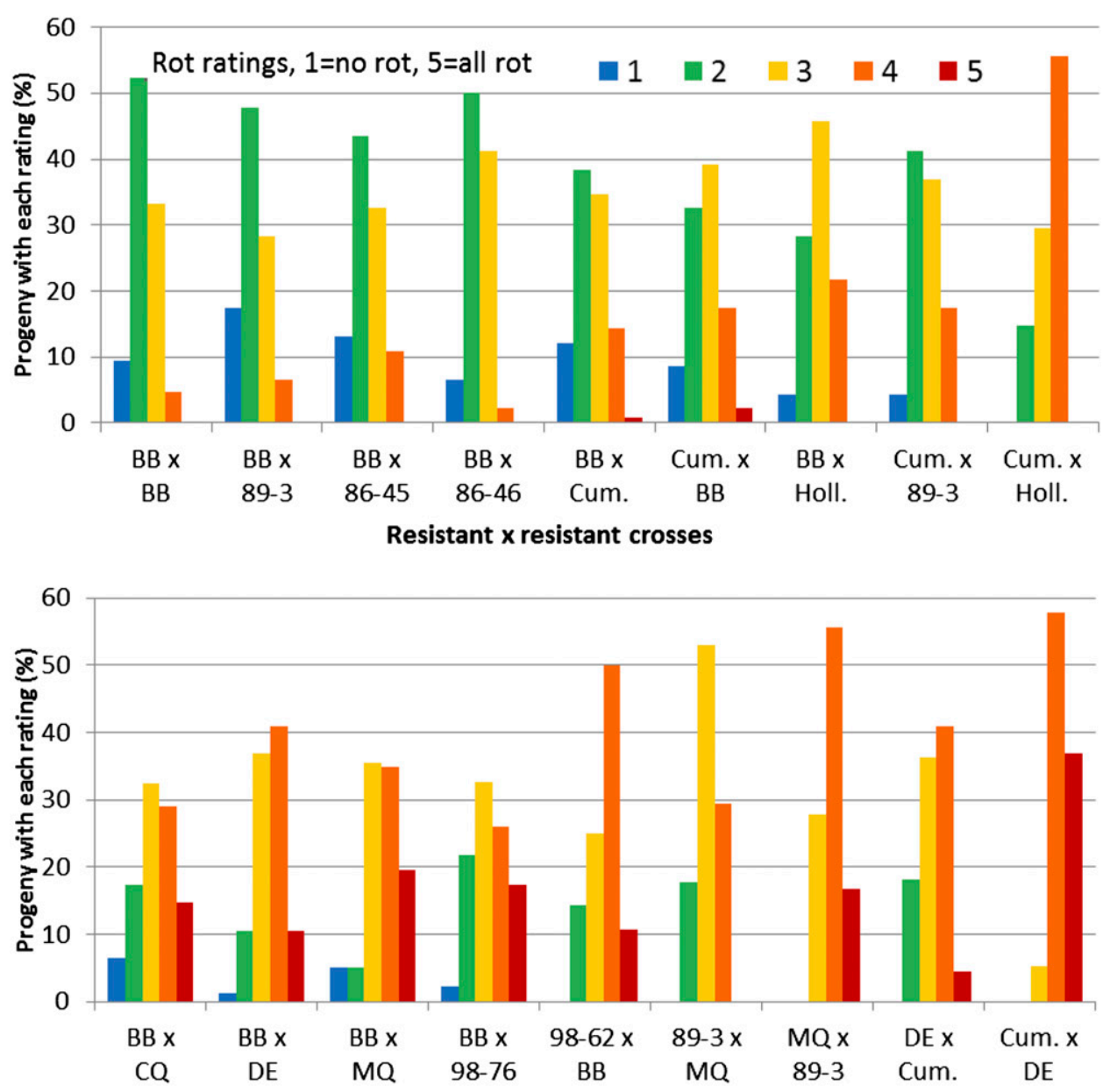

Resistant $\mathrm{x}$ susceptible crosses

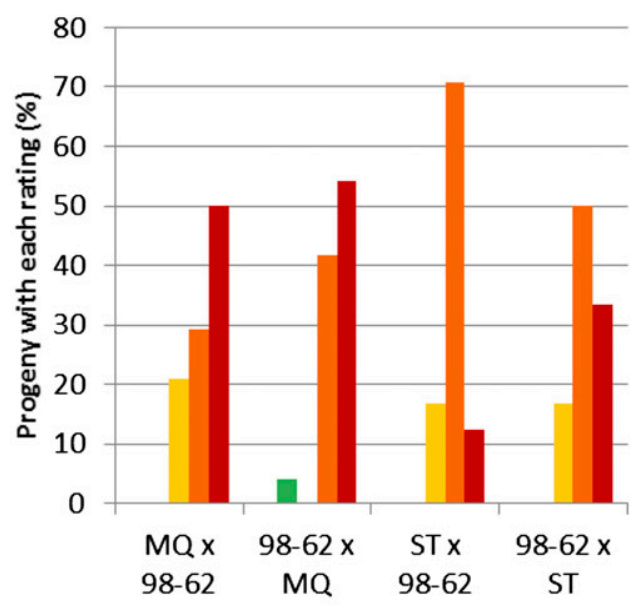

Susceptible $\mathrm{x}$ susceptible crosses

Fig. 2. Frequency distributions of progeny fruit rot ratings for select cranberry crosses, mean of 2011-13 ratings. Resistant parents are 'Budd's Blues' (BB), US89-3 (89-3), 'Cumberland' (Cum.), 'Holliston' (Holl.), CNJ97-8645 (86-45), and CNJ97-86-46 (86-46). Susceptible parents are the high-yielding cultivars Crimson Queen (CQ), Mullica Queen (MQ), Demoranville (DE), Stevens (ST), NJS98-76 (98-76), and NJS98-62 (98-62) (Table 1). highly susceptible: 'Crimson Queen', 'Mullica Queen', 'Demoranville', 'Stevens', and NJS98-62.

Differences were also found in yield $(P<0.001)$ and fruit size $(P<$ $0.001)$, important traits for commercial fruit production. 'Budd's Blues' exhibited the highest FRR, but extremely poor yield having only 70 $\mathrm{g} / 0.09 \mathrm{~m}^{2}$, as compared with the cultivar Mullica Queen, at 287 $\mathrm{g} / 0.09 \mathrm{~m}^{2}$ (Table 1). This is consistent with previous observations (years 1996-99) in fungicide-treated, unreplicated germplasm plots: 'Budd's Blues' had a mean yield of $57 \mathrm{~g} / 0.09 \mathrm{~m}^{2}$ vs. the industry standard, 'Stevens', at $338 \mathrm{~g} / 0.09$ $\mathrm{m}^{2}$. In the 1980s, crosses were made between 'Budd's Blues' and the highest-yielding cultivars at the time; e.g., Franklin and Stevens; however, only poor-yielding offspring were obtained (N. Vorsa, unpublished data). Another highly resistant parent, US89-3, has exceptionally small fruit, $0.6 \mathrm{~g} /$ berry, which contributes to its lower yield, compared with productive cultivars where the average weight is typically $1.9 \mathrm{~g} /$ berry.

Significant correlations were found between the three years of fruit rot ratings (2011 vs. 2012: $r=0.80$, $P<0.0001 ; 2011$ vs. 2013: $r=0.69$, $P<0.0001 ; 2012$ vs. 2013: $r=0.79$, $P<0.0001$ ), indicating year-to-year consistency in parental performance. A correlation was also found between rot ratings and percent rotted fruit (3-year mean, $r=0.82, P<0.0001$ ), indicating that ratings are an accurate estimate of the amount of rotted fruit.

Progeny evaluation. Severe fruit rot disease pressure occurred in the progeny evaluation plots in 2011, with an overall mean rot rating of 3.4 on 20 Sept. ( $\approx 2$ weeks before the first commercial harvest in New Jersey). Disease incidence increased each year, requiring progeny plots to be evaluated earlier each season (29 Aug. 2012 and 2 Aug. 2013). Mean fruit rot ratings were 3.7 in 2012, and 3.3 in 2013 , when over $60 \%$ of fruit overall were diseased.

Significant differences were confirmed significant differences in FRR, based on ANOVA of fruit rot ratings $(P<0.001)$ and percent rotted fruit $(P<0.001)$ (Table 1). Parents could be grouped as resistant: 'Budd's Blues', US89-3, CNJ97-86-45, and CNJ97-86-46; moderately resistant: 'Cumberland', 'Holliston', CNJ98-164-37, and CNJ98-154-26; and (Table 2). The cross that yielded the most resistant progeny ('Budd's Blues' $\times$ 'Cumberland') had a 3-year mean fruit rot rating of 2.2, whereas the cross that yielded the most susceptible progeny ('Holliston' $\times$ NJS98-76) had a mean rating of 4.5. found between families in mean fruit rot ratings $(P=0.001)$ 

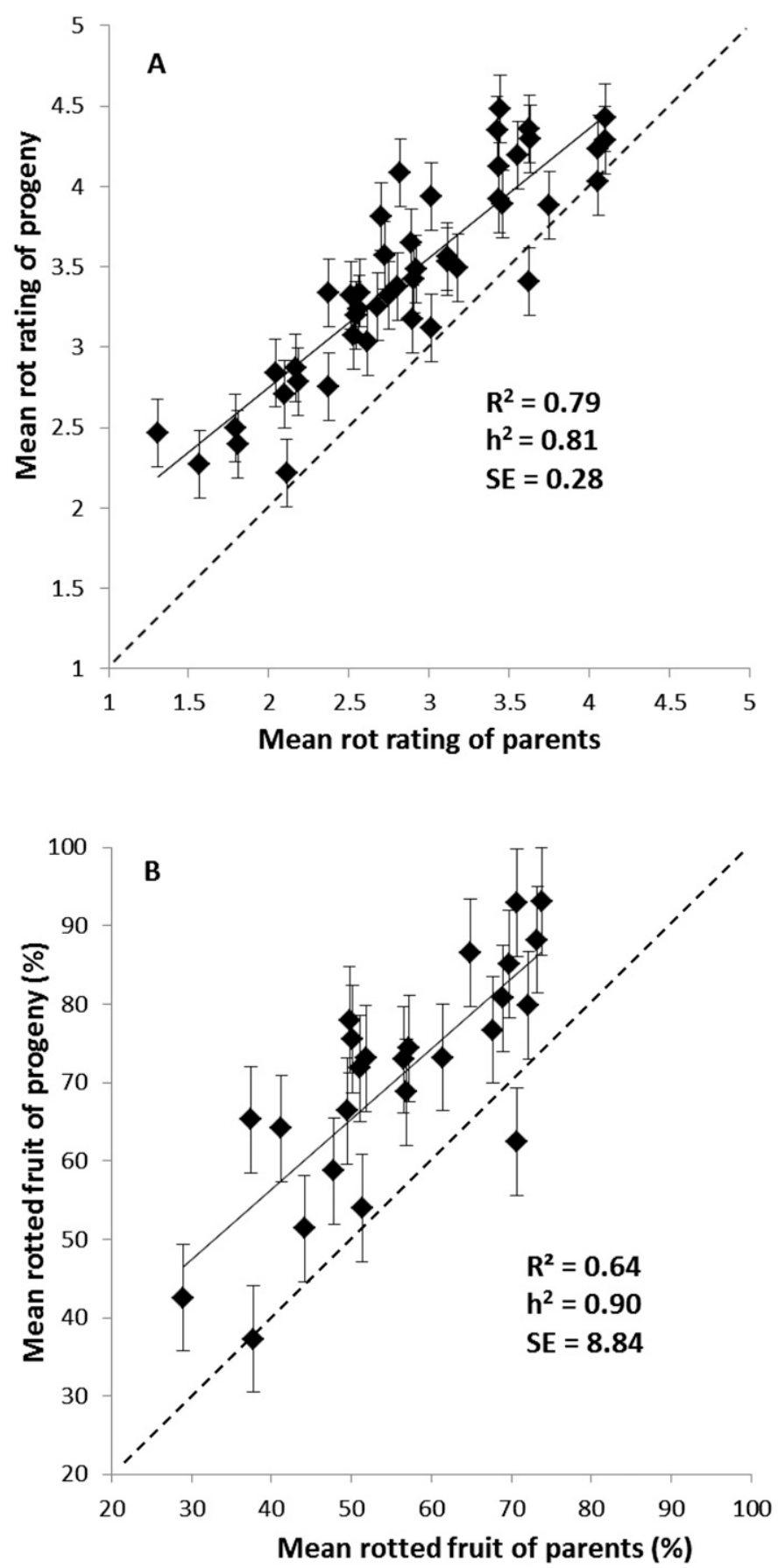

Fig. 3. Relationship between the mean of the cranberry parents and the mean of their progeny for: (A) cranberry fruit rot ratings (1-5 scale, where $1=0 \%$ to $20 \%$ rot and $5=81 \%$ to $100 \%$ rot; $n=46$ crosses), and (B) percent rotted fruit ( $n=25$ crosses); based on data collected 2011-13. Values are 3-year mean for each family $( \pm \mathrm{SE})$. Dashed line represents the predictive slope of 1 , where progeny value $=$ midparent value

There were no significant differences between years in rot ratings $(P=0.30)$, and no year by cross interaction $(P=0.77)$, so the 3-year means for each progeny and each cross are given in Figures 2-4 and Table 2. Frequency distributions of cranberry fruit rot ratings show the percentage of progeny with each rating, for each cross, and are grouped by cross type: "resistant by resistant," "resistant by susceptible," and "susceptible by susceptible" (Fig. 2). Most crosses gave progeny

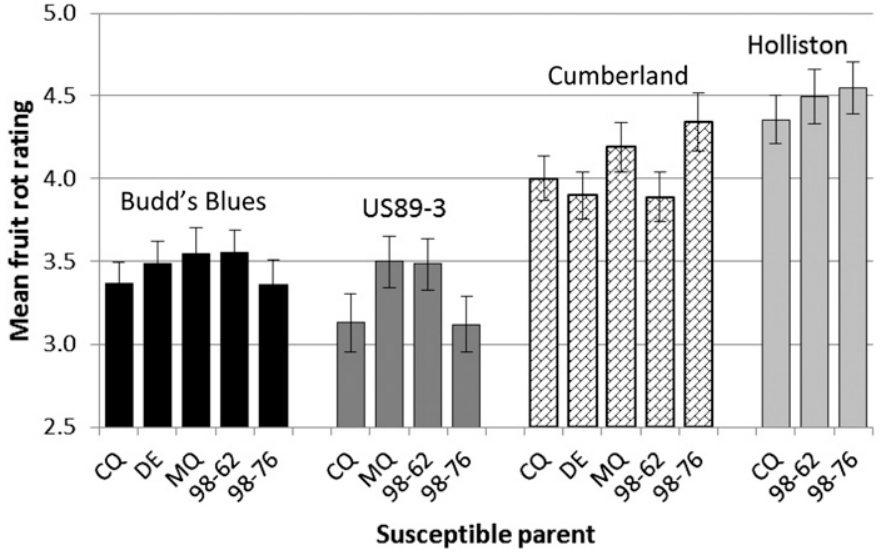

Fig. 4. Mean fruit rot ratings for resistant by susceptible cranberry crosses, grouped by resistant parent (rating scale of $1-5$, where $1=0 \%$ to $20 \%$ rot and $5=81 \%$ to $100 \%$ rot). Susceptible parents are 'Crimson Queen' (CQ), 'Demoranville' (DE), 'Mullica Queen' (MQ), NJS98-62 (98-62), and NJS9876 (98-76). Resistant parents are shown above each group. Values are 3-year mean for each family $( \pm \mathrm{SE})$.

distributions that ranged across rot rating classes. Resistant $\mathrm{x}$ resistant crosses yielded the most resistant progeny, suggesting that the diverse germplasm sources of resistance may offer complementary quantitative trait loci (QTL) for resistance and that pyramiding various resistance loci might offer greater resistance. Crosses using the highly resistant parents, 'Budd's Blues', US89-3, and CNJ97-86-45, had higher frequencies of resistant progeny. 'Budd's Blues' $\times$ 'Crimson Queen' was a particularly good cross resulting in progeny with not only good resistance but also economically viable yield. Of note, are the reciprocal crosses between US89-3 and Mullica Queen, which exhibited significantly different levels of resistance $\left(\chi^{2}=\right.$ $8.8, P=0.032$ ). With US89-3 as a maternal or seed parent, $18 \%$ of progeny had a rating of 2 (resistant), and $0 \%$ had a rating of 5 (highly susceptible), whereas US89-3 as the paternal or pollen parent, $0 \%$ were resistant, and $17 \%$ had a rating of 5 (Fig. 2). With three other sets of reciprocal crosses, where 'Budd's Blues' and 'Cumberland' were the resistant parents, no differences were found. The quantitative nature of FRR or susceptibility suggests multiple loci are involved in resistance, and susceptible plants can carry alleles for resistance. For example, a few moderately resistant progeny were found in a susceptible by susceptible cross (NJS98-62 × 'Mullica Queen') (Fig. 2).

A subset of five randomly selected progeny from each of 25 families (crosses) was sampled for percent rotted fruit, yield, and fruit size. Differences were found among the 25 crosses evaluated (percent rotted fruit $P=0.002$; yield $P=0.032$; fruit size $P=0.001$ ) (Table 2). Differences were also found among years for these traits $(P=0.001)$, due largely to different sampling dates. There was no significant interaction between cross and year. The crosses 'Cumberland' $\times$ 'Budd's Blues' and 'Budd's Blues' $\times$ CNJ97-86-45 had the lowest mean percent rotted fruit, $37.5 \%$ and $41.9 \%$, respectively (compared with 'Cumberland' $\times$ 'Demoranville' which had the highest mean rot of 92.9\%). However, these two crosses exhibiting the lowest rot were among the poorest yielding (cross means: 173 and $160 \mathrm{~g} / 0.09 \mathrm{~m}^{2}$, respectively). Mean yields for each cross varied from 362 to $159 \mathrm{~g} / 0.09 \mathrm{~m}^{2}$, and fruit weight varied from 1.8 to $1.0 \mathrm{~g} /$ berry. 
Within family variation was evident for FRR, yield, and fruit weight. Of the 1626 progeny in this study, $40 \%$ were considered highly susceptible (mean rot rating 3.8 to 5 , mean fruit rot $86 \%$ ); whereas only $3 \%$ of progeny were highly resistant (mean rot rating 1 to 1.5 , mean fruit rot $29 \%$ ), and $16 \%$ were moderately resistant (mean rot rating 1.7 to 2.5 , mean fruit $\operatorname{rot} 45 \%$ )

Since the two most resistant parents, 'Budd's Blues' and US89-3, are very low yielding, we were concerned that FRR and low yield might be pleiotropic or linked. Fortunately, our results suggest that this is not the case, as highly resistant, highyielding progeny were recovered. For example, a 'Mullica Queen' $\times$ CNJ97-86-46 progeny had a mean rot rating of 1.3, $35 \%$ fruit rot, and an economically viable yield of $328 \mathrm{~g} / 0.09$ $\mathrm{m}^{2}$, under severe fruit rot pressure (fungicide applications withheld and standard cultivars such as Stevens exhibited nearly $80 \%$ fruit rot). Furthermore, in 2014, when yield was evaluated under minimal fruit rot pressure (standard fungicide applications were made and mean percent fruit rot was $5.1 \%$, data not shown), a slight negative correlation was found between 2014 yield and 2011-13 mean fruit rot ratings for two populations segregating for resistance ('Budd's Blues' $\times$ 'Crimson Queen': $r=-0.30, P=0.002$; and 'Budds Blues' $\times$ 'Cumberland': $r=-0.26, P=0.002$ ), suggesting that yield and resistance in these two families may be slightly positively correlated.

Narrow sense heritability estimates $\left(h^{2}=0.81, \mathrm{SE}=0.28\right)$, based on midparent-offspring regression of mean fruit rot ratings, suggest significant additive genetic variance for resistance (Fig. 3A). On a subset of crosses where fruit rot was quantified $\left(n=25\right.$ crosses, percent rotted fruit per $\left.0.09 \mathrm{~m}^{2}\right)$, heritability was higher $\left(h^{2}=0.90, \mathrm{SE}=8.84\right)$; however, this estimate has a larger error due to fewer progeny being sampled (Fig. 3B). Also of note, is that the distribution of progeny means occur largely above the predictive slope of 1 (where progeny value $=$ midparent value), suggesting progeny performance is biased higher than the midparent prediction [progeny are less resistant than predicted (Fig. 3; Table 2)], indicating a recessive nature to the resistance. If there is a recessive component to resistance, then there might be value in genetic assortative matings to recover homozygous recessive backgrounds.

Heritability estimates were also calculated for yield $\left(h^{2}=0.54\right.$, $\mathrm{SE}=39.8)$ and fruit weight $\left(h^{2}=0.83, \mathrm{SE}=0.12\right)$. Heritability of yield is typically lower than for other traits (Vorsa and JohnsonCicalese, 2012). However, yield estimates in this study were confounded because of yield loss due to fruit rot or undeveloped fruit. Fruit weight, on the other hand, is usually highly heritable (Vorsa and Johnson-Cicalese, 2012), as was the case in this study.

There was moderately good correlation in the progeny fruit rot ratings between years (2011 vs. 2012: $r=0.59, P<0.0001 ; 2011$ vs. 2013: $r=0.50, P<0.0001$; 2012 vs. 2013 : $r=0.62, P<$ $0.0001)$, indicating consistency in progeny performance, and that evaluation date does not have a major impact on relative resistance of a progeny. Differences in FRR could be detected as early as 2 Aug. in 2013 and as late as 20 Sept. in 2011. Thus effective selection for resistance can be achieved throughout the later fruit development stages. There was also a correlation between fruit rot ratings and percent rotted fruit each year (2011 $r=0.79, P<$ $0.0001 ; 2012 r=0.78, P<0.0001 ; 2013 r=0.76, P<0.0001)$ and overall (3-year mean $r=0.90, P<0.0001$ ), indicating that ratings accurately reflected the amount of rotted fruit in each plot.
The diallel analysis, based on the two-way mixed effects ANOVA on fruit rot ratings of 17 resistant $\times$ susceptible crosses, indicated a significant general combining ability effect of the resistant parent $(P<0.0001)$, but not for the susceptible parent $(P=0.30)$ (Fig. 4). The interaction between resistant by susceptible parentage was not significant $(P=0.11)$, indicating specific combining ability was negligible in this set of diallel crosses, and indicating little or no epistasis. Irrespective of the susceptible, high-yielding parent, families derived from the two resistant parents, 'Budd's Blues' and US89-3, exhibited fairly high-resistance (Fig. 4).

SURVEY OF FUNGAL SPECIES PRESENT. From the 288 cranberry fruit cultured on 8 Aug. 2012, 490 fungal isolates were obtained (an average of 1.7 isolates per berry), which is consistent with previous studies (Tadych et al., 2012). Overall, the most abundant fungal species were Colletotrichum gloeosporioides (39\% of isolates), Physalospora vaccinii (10\%), and Phyllosticta vaccinii $(10 \%)$, three of the most common cranberry fruitrotting fungi (Stiles and Oudemans, 1999) (Fig. 5A). When fruit rot resistant and susceptible selections were compared, an equal number of fungal isolates were obtained overall (234 isolates vs. $245 ; P=0.27)$. Epicoccum sp. was slightly more prevalent in resistant selections ( $5 \%$ vs. $3 \%$ in susceptible; $P=0.04$ ), although this fungal species only accounted for $4 \%$ of the total isolates (Fig. $5 \mathrm{~A}$ ). When sound and rotted berries were compared (data not shown), C. gloeosporioides was recovered more often from rotted fruit $(47 \%)$ than from sound fruit $(30 \%)(P=0.03)$, as was Physalospora vaccinii $(14 \%$ vs. $7 \%)(P=0.02)$.

Berries cultured on 7 Sept. 2012 were almost all rotted and a greater number of fungal isolates were obtained (539 isolates, 1.9 isolates/berry). C. gloeosporioides and Physalospora vaccinii were more prevalent than in the August samples, at $46 \%$ and $28 \%$ of isolates, respectively; whereas Phyllosticta vaccinii (commonly called "Early Rot") was less prevalent, at 1\% of isolates (Fig. 5B). The only significant difference found between fruit of rot-resistant and susceptible selections was the greater prevalence of Physalospora vaccinii in resistant selections $(P=0.005)$.

On 21 Aug. 2013, 459 fungal isolates were obtained from the 288 berries cultured (an average of 1.6 isolates/berry). The most abundant fungal species were again $C$. gloeosporioides (38\% of isolates), Physalospora vaccinii $(25 \%)$, and Phyllosticta vaccinii (17\%) (Fig. 5C). A similar number of isolates were obtained from resistant vs. susceptible selections (225 vs. 234 isolates; $P=0.535)$; however, resistant selections had significantly fewer berries infected with C. gloeosporioides than susceptible selections $(31 \%$ vs. $44 \%, P=0.001)$. When sound and rotted berries were compared (data not shown), results were similar to those of $2012 ; 42 \%$ of the isolates from rotted fruit were $C$. gloeosporioides compared with $27 \%$ from sound fruit $(P=0.043)$, and 30\% were Physalospora vaccinii vs. 9\% in sound $(P=0.01)$. However, sound fruit had higher frequencies of Phyllosticta elongata (10\% vs. $2 \%$ in rotted fruit; $P=0.01)$. P. elongata is known to cause "berry speckle," but this species tends not to cause field fruit rot (Weidemann and Boone, 1983).

When the fruit from four highly resistant progenies were surveyed for fungal species on 21 Aug. 2013, common fruitrotting fungi were isolated from all berries (data not shown). However, about half as many isolates were $C$. gloeosporioides in the resistant progeny $(19 \%)$ as compared with susceptible cultivars (44\%), and Phyllosticta vaccinii was twice as 

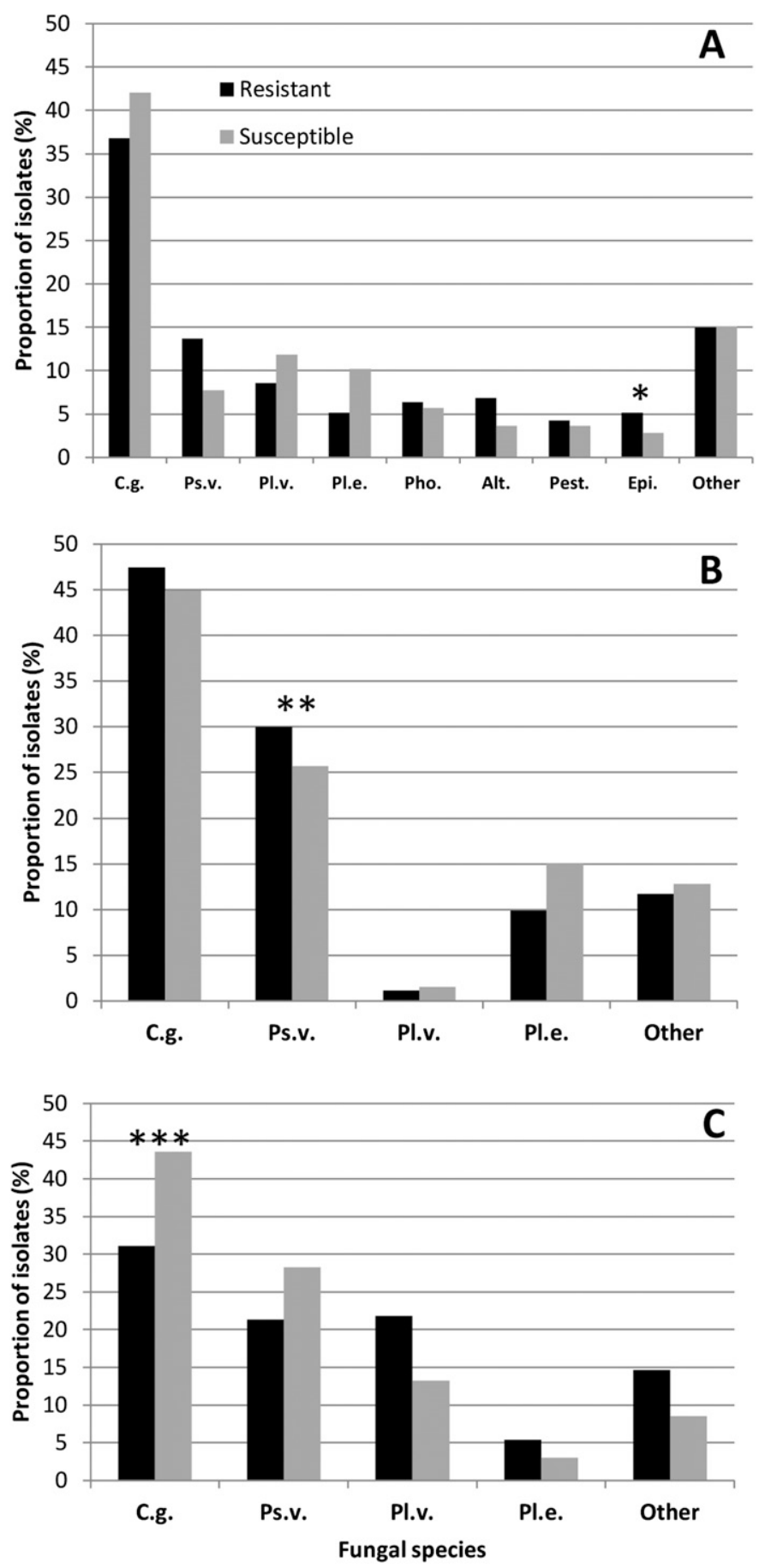

Fig. 5. Fungal species isolated from fruit rot resistant and susceptible cranberry selections. Fungal species isolated from fruit collected on (A) 8 Aug. 2012, (B) 7 Sept. 2012, (C) and 21 Aug. 2013; C.g. = Colletotrichum gloeosporioides, Ps.v. = Physalospora vaccinii, Pl.v. = Phyllosticta vaccinii, Pl.e. = Phyllosticta elongata, Pho. $=$ Phoma sp., Alt. = Alternaria sp., Pest. $=$ Pestalotia sp., Epi. = Epicoccum sp., Other $=$ various other species not identified. $*, * *, * * *$ Significant difference between resistant and susceptible selections at $P \leq 0.05,0.01,0.001$, respectively.

prevalent in the resistant progeny $(27 \%$ compared with $13 \%$ in susceptible cultivars).

Tadych et al. (2012) described the fungi (both endophytic and pathogenic) in developing cranberry ovaries from flower to mature fruit in research plots at the P.E. Marucci Center,
Chatsworth, NJ. Of the pathogenic species listed, the most common at week 10 (corresponding to 8 Aug. 2012 sampling in this study) were (in order of abundance) Phyllosticta vaccinii, Phomopsis vaccinii, Coleophoma empetri, and $C$. gloeosporiodes; at week 14 (corresponding to 7 Sept. 2012) were Physalospora vaccinii, Phyllosticta vaccinii, Phomopsis vaccinii, and C. gloeosporiodes; at week 12 (corresponding to 21 Aug. 2013), Phyllosticta vaccinii, Physalospora vaccinii, C. gloeosporiodes, Phomopsis vaccinii, and Coleophoma empetri. The fungal species isolated and their frequencies in susceptible vs. resistant fruit in Tadych et al. (2012) were similar to those found in this study, with the exception that C. empetri or Phomopsis vaccinii were not found in this study. Yearly variation in the predominant species, even from the same area, has been reported (Stiles and Oudemans, 1999). A survey of fruit from a Wisconsin cultivar trial collected on 3 Aug. 2014 found the predominant fungi were Phyllosticta vaccinii, C. gloeosporiodes, and Physalospora vaccinii (J. Polashock, unpublished data). Thus, similar species are present in Wisconsin. It is important to note that withinspecies fungal diversity across growing regions was found to be low (Polashock et al., 2009). This reiterates the importance of breeding for broad spectrum resistance as opposed to fungal species-specific resistance, but it also suggests that the resistance for which we are breeding will be effective in other growing regions. In fact, in Washington and Wisconsin fruit rot trials, the resistant parents used in this study had lower percent rotted fruit compared with susceptible controls, in 2013 and 2014 (K. Patten and N. Vorsa, unpublished data).

The findings of this study suggest that the four diverse germplasm sources of FRR may offer complementary FRR QTL, and their introgression and pyramiding in genetically productive backgrounds should provide future genetic gain for FRR and crop productivity.

\section{Literature Cited}

Bruederle, L.P., M.S. Hugan, J.M. Dignan, and N. Vorsa. 1996. Genetic variation in natural populations of the large cranberry, Vaccinium macrocarpon Ait. (Ericaceae). Bull. Torrey Bot. Club 123:41-47.

Byrne, D.H. 2012. Trends in fruit breeding, p. 3-36. In: M.L. Badenes and D.H. Byrne (eds.). Fruit breeding. Springer, New York, NY.

California Office of Environmental Health Hazard Assessment. 2015. Proposition 65. 2 Feb. 2015. <http://oehha.ca.gov/prop65.html>.

Chandler, F.B. and I. Demoranville. 1958. Cranberry varieties of North America. Univ. Massachusetts College Agr. Expt. Sta. Bul. 513. Dana, M.N. 1983. Cranberry cultivar list. Fruit Var. J. 37:88-95.

Eck, P. 1990. The american cranberry. Rutgers Univ. Press, New Brunswick, NJ.

European Commission. 2015. EU Pesticides Database. 2 Feb. 2015. $<$ http://ec.europa.eu/sanco_pesticides/public/?event=pesticide. residue.selection\&language $=\mathrm{EN}>$.

Falconer, D. 1989. Introduction to quantitative genetics. 3rd ed. Wiley, New York, NY.

Felsenstein, J. 2009. PHYLIP (Phylogeny Interference Package), ver. 3.69. Univ. Washington, Seattle, WA.

Georgi, L., R.H. Herai, R. Vidal, M.F. Carazzolle, G.G. Pereira, J.J. Polashock, and N. Vorsa. 2012. Cranberry microsatellite marker development from assembled next-generation genomic sequence. Mol. Breed. 30:227-237.

Georgi, L., J. Johnson-Cicalese, J. Honig, S. Das, V. Rajah, D. Bhattacharya, N. Bassil, L.J. Rowland, J.J. Polashock, and N. Vorsa. 2013. The first genetic map of the american cranberry: Exploration of 
synteny conservation and quantitative trait loci. Theor. Appl. Genet. 126:673-692.

Johnson-Cicalese, J., N. Vorsa, and J. Polashock. 2009. Breeding for fruit rot resistance in Vaccinium macrocarpon. Acta Hort. 810:191-198.

Johnson-Cicalese, J., N. Vorsa, J. Polashock, L. Georgi, and M. Tadych. 2011. Evaluating cranberry progeny for field fruit rot resistance. North Amer. Cranberry Res. Ext. Conf., Wisconsin Rapids, WI, 11-14 Sept. 2011. p. 9. (Abstr.).

Liu, K. and S.V. Muse. 2005. PowerMarker: An integrated analysis environment for genetic marker analysis. Bioinformatics 21:21282129.

McManus, P. 2006. Cranberry fruit rot players in 2005. 2 Feb. 2015. $<$ http://fruit.wisc.edu/wp-content/uploads/2011/05/Cranberry-FruitRot-Players-in-2005.pdf $>$.

McManus, P.S. 1998. First report of early rot on cranberry caused by Phyllosticta vaccinii in Wisconsin. Plant Dis. 82:350.

Oudemans, P., F. Caruso, and A. Stretch. 1998. Cranberry fruit rot in the Northeast: A complex disease. Plant Dis. 82:1176-1184.

Polashock, J. and N. Vorsa. 2002. Development of SCAR markers for DNA fingerprinting and germplasm analysis of american cranberry. J. Amer. Soc. Hort. Sci. 127:677-684.

Polashock, J.J., F.L. Caruso, P.V. Oudemans, P.S. McManus, and J.A. Crouch. 2009. The North American cranberry fruit rot fungal community: A systematic overview using morphological and phylogenetic affinities. Plant Pathol. 58:1116-1127.

Schuelke, M. 2000. An economic method for the fluorescent labeling of PCR fragments. Nat. Biotechnol. 18:233-234.
Stewart, C.N. and L.E. Via. 1993. A rapid CTAB DNA isolation technique useful for RAPD fingerprinting and other PCR applications. Biotechniques 5:748-750.

Stiles, C.M. and P.V. Oudemans. 1999. Distribution of cranberry fruitrotting fungi in New Jersey and evidence for nonspecific host resistance. Phytopathology 89:218-225.

Tadych, M., M. Bergen, J. Johnson-Cicalese, J. Polashock, N. Vorsa, and J. White. 2012. Endophytic and pathogenic fungi of developing cranberry ovaries from flower to mature fruit: Diversity and succession. Fungal Divers. 54:101-116.

Tamura, K., G. Stecher, D. Peterson, A. Filipski, and S. Kumar. 2013. MEGA6: Molecular evolutionary genetics analysis version 6.0. Mol. Biol. Evol. 30:2725-2729.

University of Massachusetts. 2012. A record warm winter and heavy fruit rot incidence. Notes from the tenth annual cranberry summit. 2 Feb. 2015. $<$ http://www.umass.edu/cranberry/downloads/newsletters/dec12.pdf $>$.

Vander Kloet, S.P. 1983. The taxonomy of Vaccinium section Oxycoccus. Rhodora 85:1-43.

Vorsa, N. 2010. Cranberry, p. 728. In: J.R. Clark and C.E. Finn (eds.). Register of new fruit and nut cultivars, List 45. HortScience 45:716-756.

Vorsa, N. 2012. Cranberry, p. 543. In: J.R. Clark and C.E. Finn (eds.). Register of new fruit and nut cultivars, List 46. HortScience 47:536-562.

Vorsa, N. and J. Johnson-Cicalese. 2012. American Cranberry, p. 191223. In: M.L. Badenes and D.H. Byrne (eds.). Fruit breeding. Springer, New York, NY.

Weidemann, G.J. and D.M. Boone. 1983. Incidence and pathogenicity of Phyllosticta vaccinii and Botryosphaeria vaccinii on cranberry. Plant Dis. 67:1090-1093. 